IAEA Safeguards for the Fissile

Materials Disposition Project

D. A. Close 


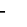




\section{DISCLAIMER}

This report was prepared as an account of work sponsored by an agency of the United States Government. Neither the United States Government nor any agency thereof, nor any of their employees, make any warranty, express or implied, or assumes any legal liability or responsibility for the accuracy, completeness, or usefulness of any information, apparatus, product, or process disclosed, or represents that its use would not infringe privately owned rights. Reference herein to any specific commercial product, process, or service by trade name, trademark, manufacturer, or otherwise does not necessarily constitute or imply its endorsement, recommendation, or favoring by the United States Government or any agency thereof. The views and opinions of authors expressed herein do not necessarily state or reflect those of the United States Government or any agency thereof. 


\section{DISCLAIMER}

Portions of this document may be illegible in electronic image products. Images are produced from the best available original document. 


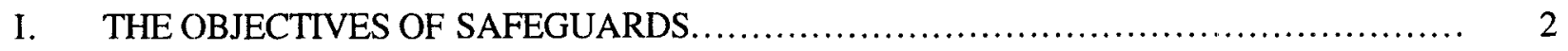

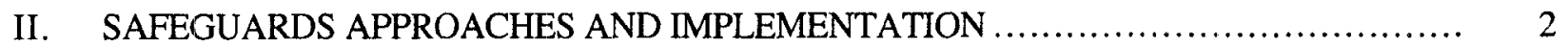

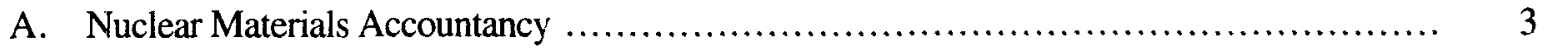

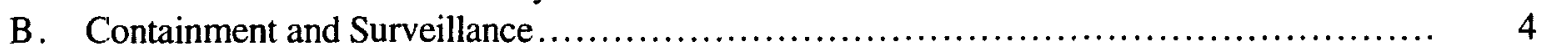

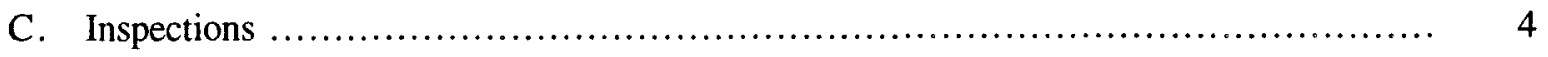

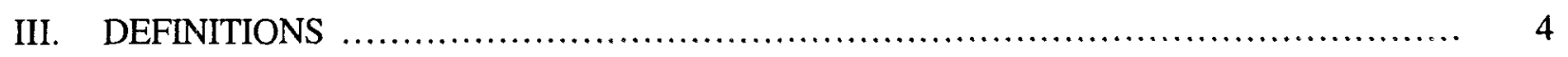

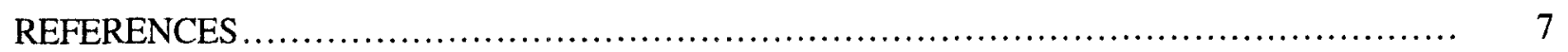





\title{
IAEA SAFEGUARDS FOR THE FISSILE MATERIALS DISPOSITION PROJECT
}

\author{
by \\ D. A. Close
}

\begin{abstract}
This document is an overview of International Atomic Energy Agency (IAEA) safeguards and the basic requirements or elements of an IAEA safeguards regime. The primary objective of IAEA safeguards is the timely detection of the diversion of a significant quantity of material and the timely detection of undeclared activities. The two important components of IAEA safeguards to accomplish their primary objective are nuclear material accountancy and containment and surveillance. This overview provides guidance to the Fissile Materials Disposition Project for IAEA inspection requirements. IAEA requirements, DOE Orders, and Nuclear Regulatory Commission regulations will be used as the basis for designing a safeguards and security system for the facilities recommended by the Fissile Materials Disposition Project.
\end{abstract}

The following discussion is an overview of International Atomic Energy Agency (IAEA) safeguards and the basic requirements or ele ments of an IAEA safeguards regime. The primary objective of IAEA safeguards is the timely detection of the diversion of a significant quan tity of material and the timely detection of undeclared activities. IAEA safeguards is not de signed to prevent or deter unauthorized possession of nuclear materials. The two important components of IAEA safeguards to accomplish their primary objective are nuclear material ac countancy and containment and surveillance. Many of the specifics of IAEA safeguards are presented here as selected definitions at the end of the overview. All the information is taken from the references listed at the end of this paper.

Basic outlines of the essentials of the IAEA safeguards approach for various "typical" important nuclear facilities are discussed in Ref. 1 . These are modified as required for individual specific facilities. These model facilities include the following: light water power reactors; research reactors; critical assemblies; on-load-fueled power reactors; fast breeder reactors; storage facilities; conversion and fuel fabrication plants for lowenriched uranium, high-enriched uranium, and mixed oxides; reprocessing plants; and enrichment plants. Some of the selected technologies for the Fissile Materials Disposition Project are not included in the above list and may not have been explicitly considered by the IAEA.

This overview provides guidance to the Fissile Materials Disposition Project for IAEA inspection requirements as different options for material disposition are considered for the Programmatic Environmental Impact Statement and the Record of Decision. This overview, along with the appropriate DOE Orders and Nuclear Regulatory Commission (NRC) regulations, will be used as the 
basis for designing a safeguards and security system for the facilities recommended by the Fissile Materials Disposition Project. This will ensure that the requirements of the DOE, IAEA, and NRC are satisfied for the different options.

An important issue for an IAEA inspection that is not addressed here but can have a poten tial major impact on the facility is classification. Classified information must be protected during an inspection by IAEA inspectors. These classification issues have been discussed in Ref. 2 .

\section{THE OBJECTIVES OF SAFEGUARDS}

"Safeguards are essentially a technical means to verify the fulfillment of political obligations undertaken by States in concluding international agreements relating to the peaceful uses of nuclear energy. Today most of these obligations flow from the NPT and similar agreements." [Ref. 3, p. 12.]

"The agreement [between the Agency and the State] should provide that the objective of safeguards is the timely detection of diversion of significant quantities of nuclear material from peaceful nuclear activities to the manufacture of nuclear weapons, other nuclear explosive de vices, or for unknown purposes, and the deterrence of such diversion by the risk of early detection." [Ref. 4, p. 9.]

"In NPT States (and increasingly in others as well), the IAEA nuclear materials accountancy and verification are based on reports submitted by the State's system of accounting for and control of nuclear materials as well as on records kept at facilities." [Ref. 3, p. 16.] Mechanisms exist to resolve anomalies and discrepancies, which may be detected by the IAEA.

\section{SAFEGUARDS APPROACHES AND IMPLEMENTATION}

"The provisions necessary to implement the facility safeguards approach are incorporated in the Safeguards Agreement and, where applicable, in the Subsidiary Arrangements and the Facility Attachments." [Ref. 1, p. 23.]

"The Agreement should provide that the technical conclusion of the Agency's verification [and inspection] activities shall be a statement ... [for] each material balance area of the amount of material unaccounted for over a specific period, giving the limits of accuracy of the amounts stated." [Ref. 4, p. 9.] Following are the main components of the safeguards approach:

1. design and operation characteristics of the facility relevant to safeguards;

2. an MBA structure covering the facility and a set of strategic points, in particular key measurement points;

3. plausible diversion and concealment assumptions ... ;

4. inspection goals reflecting the actual conditions at the facility and the given legal and technical constraints;

5. recording and reporting requirements;

6. special nuclear material accountancy features, such as requirements, procedures, and timing for verification of the quantity, composition, and location of nuclear material;

7. appropriate combinations of containment and surveillance measures and the strategic points at which they are to be applied;

8. the number. duration. timing, and mode of routine inspecuons:

9. the set of inspection activities to be carried out during routine inspections in a typical nuclear material [reporting period]." [Ref. 1, p. 23.]

Safeguards practices can be summarized in one word: verification. To verify means 'to establish the truth of.' In safeguards, to verify is to establish the truth of statements regarding the amounts, presence and use of nuclear material or other items subject to safeguards as recorded by facility operators and as reported by the State to the IAEA. [Nuclear material] accountancy, taken together with containment and surveillance, is the fundamental basis on which verification rests." [Ref. 3, p. 19.] "Nuclear material accountancy ... [and] 
containment and surveil lance ... [are] important complementary measures." [Ref. 1, p. 8.]

The verification process can be described as consisting of three distinct stages:

1. The examination of the information provided by the State in

a. design information describing installations under safeguards;

b. accounting reports listing nuclear material inventories, receipts, and shipments;

c. documents amplifying and clarifying reports;

d. advance notification of international transfers of material.

2. The collection of information by the IAEA as a result of

a. inspections for the verification of the design information;

b. inspections to examine records and reports and inspection of nuclear material;

c. special inspections in case of unusual findings.

3. The evaluation of the information provided by the State and of that collected by inspectors, to determine the completeness, accuracy, and validity of the information provided by the State." [Ref. 3, pp. 19-20.]

\section{A. Nuclear Materials Accountancy}

It is the purpose of nuclear materials accounting to establish the quantities of nuclear material present within defined areas and the changes in these quantities that take place within defined periods of time. The essential elements of such accounting are:

1. The operator identifies and counts or measures the material in the area concerned.

2. The operator keeps records of all transactions involving this material.

3. The operator prepares accounting reports on these transactions and submits these reports via the State to the IAEA.

4. The IAEA verifies and analyzes the data in these reports to determine their cor rectness and to assess the amount of any material unaccounted for and evaluate the causes of any such material unaccounted for.

To make these tasks more manageable, material balance areas (MBAs) are established in nuclear installations. These MBAs are areas into and out of which all transfers can be determined and in which physical inventories can be taken to establish a nuclear material balance. ... Within MBAs measurements are made at key measurement points (KMPs), which are locations where nuclear material may be measured for the determination of flow or inventory.

Accountancy in IAEA terms begins in practice with the determination by the operator of the initial physical inventory for a facility or MBA and the recording of that inventory in a book in which the operator thereafter records subsequent inventory changes." [Ref. 3, p. 20.] Material accountancy is based on measurements of material transfers and physical inventories. The results of periodic physical inventories by the operator and their relation to corresponding book inventories are fundamental to nuclear material accountancy. "Any difference between the book inventory and the physical inventory is called 'material unaccounted for' (MUF). The reasons for MUF may be found in measurement uncertainties or other technical causes. If the size of the MUF is found to be beyond a value attributable to such identifiable causes, the possibility that a diversion has been made must be considered." [Ref. 3, p. 21.]

On the basis of operators' nuclear material accountancy [NMA] activities, the State submits periodic accounting reports to the IAEA, namely:

1. Inventory Change Reports which de scribe each increase and decrease of nuclear material in each MBA since the last report;

2. Material Balance Reports (MBR) accompanied by physical inventory listings submitted after each physical inventory and containing the MUF analysis." [Ref. 1, p. 10.] 


\section{B. Containment and Surveillance}

Containment measures take advantage of physical barriers such as walls, containers, tanks or pipes, to restrict or control the movement of or access to nuclear material. Such measures help to reduce the probability that undetected movements of nuclear material or equipment can take place. Containment measures may involve the application of devices such as uniquely identified tamperindicating seals to ensure that any change in the sealed inventory will be detected.

Surveillance means both human and instrumental observation in order to detect undeclared movements of nuclear material, tampering with containment, fabrication of false information or tampering with safeguards devices. Surveillance may involve the use of tamper-resistant automatic cameras [or closed circuit TV systems, radiation and motion detectors, and tamper-indicating seals] or other devices to monitor changes in containment or to observe changes. Personnel may carry out the same tasks by manning key observation points continuously or periodically." [Ref. 3, pp. 24-25.]

\section{Inspections}

Inspections are essential to implement the safeguards measures described above. The aim is to verify the validity of information in the possession of the Agency .... During inspections the IAEA's inspectors carry out numerous tasks, including:

1. examine pertinent records;

2. make independent measurements of safeguarded nuclear material;

3. verify the proper functioning and calibration of equipment;

4. obtain samples and ensure that they are properly collected, tested, handled, and shipped;

5. use and service IAEA surveillance equipment;

6. affix, inspect, and remove IAEA seals;" [Ref. 3, p. 26.] and

7. verify inventories.

\section{DEFINITIONS}

The following definitions were selected from the references to indicate the general aspects of an Agency inspection as appropriate for the different facilities considered for the Fissile Materials Disposition Project. Unless stated ex plicitly, the definitions are taken from Refs. 5 and 6.

A. Accountancy verification goal - "the mini mum quantity of nuclear material which, if di verted at a facility, should ... be detected by the application of nuclear material accountancy measures along with a low risk of false alarm. ... [For] item facilities, ... the goal is equal to 1 significant quantity of nuclear material. ... [For] bulk handling facilities, ... the goal depends on the nature of the facility, the quantities of material handled, and the effect of measure ment uncertainties. ..." [Ref. 1, p. 6.]

B. Defect - difference between the declared amount of nuclear material ... and the actual amount present:

1. bias defect - refers to a difference between the amount of nuclear material actually present in an item and the amount declared to be present, which is a fraction of the declared amount, ... determined by the most precise measure ment method available;

2. gross defect - an item that has been fal sified to the maximum extent possible, i.e., all of the nuclear material is missing;

3. partial defect - refers to a difference between the amount of nuclear material actually present in an item and the amount declared to be present, which is a fraction of the declared amount.

C. Detection probability - the assurance given by safeguards measures expressed as the overall probability of detecting the absence of a specified quantity of nuclear material. The detection probabilities specified for nuclear material verifications ... have the following meanings: 


$\begin{array}{ll}\text { High } & 90 \% \\ \text { Medium } & 50 \% \\ \text { Low } & 20 \%\end{array}$

D. Detection time - corresponds approximately to the conversion time, which is the "time neces sary to convert different forms of nuclear material to the metallic components of a nuclear explosive device. Conversion time values used at present range from 7 to 10 days for metallic plutonium to one year for natural uranium." [Ref. 1, p. 5.]

\section{E. Inspections}

1. Ad-hoc inspection - "inspection made to verify information submitted by States regarding the design of new nuclear facilities, the first report made by the State after the conclusion of the safeguards agreement and changes between the submission of that first report and the beginning of routine inspections. ..." [Ref. 3, p. 26.]

2. Routine inspection - "inspection made to verify that the information contained in reports submitted by the State is con sistent with the accounting and operating records kept by the operator. Routine inspection also verifies the amount, the location and the identity of nuclear material, investigates shipper/ receiver differences, ... uncertainties in book in ventories, and MUF." [Ref. 3, p. 26.]

3. Special inspection - "inspection made in addition to routine inspection when unusual circumstances occur and are notified to the Agency in special reports, or in order to collect information in addition to that which the State routinely provides or which is obtained by routine inspections but is found to be inadequate. ..." [Ref. 3, p. 26.]

F. Installation categories - installations are divided into facilities as follows:

1. Light water reactors;

2. On-load fueled power reactors;

3. Other power reactors;

4. Research reactors and critical assemblies;
5. Natural and low enriched uranium conversion and fabrication plants;

6. Fabrication plants handling direct-use material;

7. Reprocessing plants;

8. Enrichment plants;

9. Storage facilities - facilities for storing nuclear material or non-nuclear material not directly connected with a reactor, fabrication, or reprocessing facility;

10. Other facilities - facilities not included above including research and development facilities, where nuclear material in amounts greater than one effective kilogram is customarily used;

11. Heavy water production plant.

G. Key measurement point - "a location where nuclear material appears in such a form that it may be measured to determine material flow or inventory. Key measurement points include ... the inputs [to], outputs [from], and storage [locations] in material balance areas." [Ref. 4, p. 28.]

H. Material category - nuclear material is divided into categories as follows, according to its suitability for conversion into nuclear explosives components and to its irradiation status:

1. [non-irradiated] direct-use material - . . material which doès not contain substantial amounts of fission products. This includes purified plutonium and ura nium enriched to $20 \%$ or above; it also includes reprocessing plant solutions from the dissolver onwards. Fuel containing direct-use material is considered as [non]-irradiated for verification and timely detection purposes until it is placed in a reactor core.

2. irradiated direct-use material - ... material which contains substantial amounts of fission products. This includes core fuel and spent fuel.

3. indirect-use material - [material including] uranium enriched to less than $20 \%$, natural uranium, depleted uranium, and thorium. DNLEU core and spent fuel at research reactors where reporting of plutonium 
production is not required is considered to be indirect-use material.

Categories of non-nuclear material under safeguards are heavy water, zircalloy tubes, and nuclear grade graphite.

I. Material form - classification of nuclear material according to its physical form as follows:

1. item - an identifiable unit, e.g., fuel assembly, fuel pin, plate, or coupon;

2. bulk material - material in loose form, in liquids, gases, powders, or in large numbers of non-identifiable units (e.g., pel lets, pebbles);

3. other nuclear material - ... nuclear material other than the fuel used in the reactors [and] at research reactors and critical assembly facilities.

J. Material type - classification of nuclear material according to the element contained and, for uranium, the enrichment:

1. DNLEU - depleted, natural, and low-enriched uranium

2. HEU

3. ${ }^{233} \mathrm{U}$

4. Plutonium

5. Thorium

K. Significant quantity [SQ]- the approximate quantity of nuclear material in respect of which the possibility of manufacturing a nuclear explosive device cannot be excluded. Significant quantity values currently in use are as follows:

\section{Material Type}

$1 \mathrm{SQ}$

1. $\mathrm{Pu}$ $8 \mathrm{~kg} \mathrm{Pu}$

2. HEU ( $20 \%$ enriched and above)

3. ${ }^{233} \mathrm{U}$ $25 \mathrm{~kg} 235 \mathrm{U}$

4. LEU (less than $20 \%$ enriched, including natural $\mathrm{U}$ and depleted $\mathrm{U}$ )

$8 \mathrm{~kg} 233 \mathrm{U}$

$75 \mathrm{~kg}{ }^{235} \mathrm{U}$ (or $10 \mathrm{t}$ natural $\mathrm{U}$ or $20 \mathrm{t}$ depleted U)

5. Thorium

$20 \mathrm{t}$ thorium
L. Timeliness goal - the period of time used as the objective for timely detection of a diversion, established by nuclear material category as follows:

1. 1 month for non-irradiated direct-use material;

2. 3 months for irradiated direct-use material;

3. 1 year for indirect-use material and for directuse material types with less than 1 significant quantity inventory.

The timeliness goal is reflected in the required number of verifications per year.

1. 12 [verifications] for 1 significant quantity or more of non-irradiated direct-use material;

2. 4 [verifications] for 1 significant quantity or more of irradiated direct-use material;

3. 1 verification in other cases (indirect-use material and for direct-use material types with less than 1 significant quantity inventory).

M. Verification methods - the methods used by the Agency to verify nuclear and non-nuclear material:

1. Accountancy verification methods Identification ...

Weighing

Volume determination

Sampling and analysis

Variables by NDA (bias defects)

Variables by NDA in attribute mode (partial defects)

Attribute test by NDA (gross defects)

Facility specific method for in-process inventory verification

2. Methods reflecting containment and surveillance measures

Seal verification

Monitors [including video, radiation, motion]

3. Other methods

Item counting (optionally using random selections)

Spent fuel inventory check for verification

Tag check

Other [facility and material specific techniques] 


\section{REFERENCES}

1. IAEA Safeguards: Implementation At Nuclear Fuel Cycle Facilities (IAEA, Vienna, 1985), IAEA/SG/INF/6.

2. C. M. Frankel, D. A. Close, B. H. Erkilla, G. P. Estes, and W. D. Stanbro, "Classification Issues Related to the Radiation Detection Techniques in Transparency/Safeguards," (U) Los Alamos National Laboratory report LA12723-MS (1993). This report is SRD.

3. IAEA Safeguards: An Introduction (IAEA, Vienna, 1981) IAEA/SG/INF/3.
4. The Structure And Content Of Agreements Between The Agency And States Required In Connection With The Treaty On The NonProliferation Of Nuclear Weapons (IAEA, Vienna, 1972), INFCIRC/153.

5. "Safeguards Criteria 1991-1995," Department of Safeguards report, International Atomic Energy Agency, Vienna, 1990.

6. IAEA Safeguards Glossary, 1987 Edition (IAEA, Vienna, 1987), IAEA/SG/INF/1 (Rev. 1). 